\title{
Repasos solemnes y lecciones ordinarias. Textos manuscritos sobre la Sagrada Escritura (1536-1539). Segunda parte ${ }^{1}$.
}

\author{
Domingo De Soto O.P. \\ IgnACIO JeRICó BeRMEJO².
}

\section{Palabras clave:}

Artículo de fe, canon sagrado, Domingo de Soto, lección (pre-lección), manuscritos, reforma de la Iglesia, repaso solemne (re-lección).
Solemne revisions and ordinary lessons. Handwritten texts on Sacred Scripture (1536-1539)

\section{Keywords:}

Article of faith, sacred canon, Domingo de Soto, ordinary lesson (pre-lectio), manuscripts, reform of the Church, solemn revisión (relection).

\section{Dos textos de lecciones ordinarias (prae-lectio) (1539)}

a) Ott. lat. 782

[L.a.1] Después de que tenemos nosotros que pueden crecer los artículos con la sucesión del tiempo en orden a dirimir las herejías nuevas, se pregunta ahora a quién pertenece redactar los artículos nuevos, si ello pertenece al Sumo Pontífice. Y responde Santo Tomás afirmativamente. Y lo prueba en primer lugar por el argumento que pone en contra de los que se oponen a la admisión. Porque la edición del símbolo se hizo en un concilio general. Así queda patente en el concilio de Nicea. Ahora bien, el concilio se congrega con

${ }^{1}$ Como ya se comentó en ATG 81 (2018), en esta segunda parte, se editan las traducciones al castellano de los manuscritos de la lección ordinaria (prae-lectio) de 1539, siguiendo el ms. Ott. lat. 782 de la Biblioteca Apostólica Vaticana (Roma) y según el ms. 940 de la Biblioteca Nacional de México. Está prevista la publicación de los originales latinos de las re-lectiones y de la prae-lectio.

\footnotetext{
${ }^{2}$ Investigador. Universidad de Navarra-Peralta (Navarra). https://orcid.org/0000-0002-8524-8261.
} 
la autoridad del Papa. Es lo que se tiene por toda la distinción decimoséptima. Por consiguiente, se extrae la consecuencia.

[L.a.2] En segundo lugar, porque el artículo de fe no es más que cierta determinación que se propone para ser creída en contra de alguna herejía. Ahora bien, corresponde al Sumo Pontífice la determinación de las dudas de la fe. Así se tiene en la 24, cuestión 1, c. se pregunta. Ciertamente, hay una errata en la letra de Santo Tomás. Es que no está tal palabra en la distinción cuarenta y dos. Lo mismo se tiene en y los mayores, que trata sobre el bautismo y su efecto.

[L.a.3] Muy grave es esta cuestión. Y la dificultad queda puesta en contra de los herejes. Está también planteada la misma entre algunos católicos. Ya tratamos nosotros de ella más ampliamente, en la relección mía Sobre la autoridad de la Sagrada Escritura. Repetiré yo algunas cosas que dijimos allí y añadiré otras. Lo primero de todo. Decía Wiclef en el Sermón cuarenta y cinco, como lo refiere el Waldense en un capítulo del tomo primero del Libro segundo, que ni el Papa, ni la Iglesia toda, tiene la autoridad de redactar los artículos de la fe, ni la de determinar algo como de fe, sacándolo desde la Sagrada Escritura. Queda patente esto. Es que se determinaron muchas cosas de fe en el concilio de Nicea, las cuales no estaban antes como expresadas de fe con la categoría de artículo. Así, el que Cristo es Dios de la misma sustancia del Padre, que la bienaventurada Virgen es verdaderamente la madre de Dios, etc.

[L.a.4] Ahora bien, se confirma por la autoridad de la Sagrada Escritura. Efectivamente, se dice: "He aqui que yo estoy con vosotros hasta la consumación del mundo" (Mt 28,20). Y: "Yo rogaré al Padre, y os dará otro Abogado, que estará con vosotros para siempre” (Jn 14,16). Y no era con todo una necesidad que Cristo y el Espíritu Santo permanecieran siempre en la Iglesia si no era para gobernar la Iglesia y para exponer principalmente la Escritura que el mismo Espíritu Santo había revelado.

[L.a.5] Y se prueba por la razón. Es que hubo de actuar así Cristo, a no ser que hubiera cambiado previamente las condiciones de los hombres tan clara y perspicuamente que es fuera imposible a algunos hombres extraer otros sentidos de las Sagradas Escrituras. Por supuesto, es tal la condición humana. De esta forma, hay tantas cabezas como sentidos. Arrio extrajo de esta forma que Cristo no era Dios. Lo hizo desde aquella frase: "El Padre es mayor que yo" (Jn 14,28). Y extrajo Sabelio que el Hijo era la misma persona con el Padre de aquella frase: "Yo y el Padre somos una sola cosa" (Jn 10,30). Por tanto, hubo necesidad de que Cristo dejara en la Iglesia la autoridad de explicar la Sagrada Escritura de forma que tal exposición fuera de fe.

[L.a.6] Ahora bien, responden los herejes que aquello no es necesario. Al contrario, que cuando hubiera una duda, habría de esperarse una revelación 
inmediatamente desde Dios. De todas formas, se arguye que esto es algo intolerable. Es que, si al surgir una duda ha de esperarse una revelación, debería hacerse esa segunda revelación a las personas singulares que dudan o debería hacerse a uno que la enunciara a los demás. Sería absurdo y fatuo decir lo primero; por ejemplo, que cada uno que dudara debería esperar revelaciones especiales.

[L.a.7] Y si se dice lo segundo, aparece entonces un argumento que necesita respuesta. Porque sería muy cierto y de fe que aquél al que se le hiciera la revelación podría engañar a los demás o no podría. Si no fuera esto muy cierto, permaneceríamos entonces todavía siempre dudosos de si aquél nos decía lo verdadero, dando lugar entonces a cismas entre los hombres, en contra del precepto de Pablo del capítulo primero de la primera a los Corintios. Ahora bien, si fuera de fe que aquél no puede engañarnos, no puede ciertamente ser el mismo otro que el Papa o el concilio. Y de esta manera, no se ha de dudar de que la Iglesia puede determinar algo como de fe.

[L.a.8] De todas formas, hay una segunda duda ¿Cuál es esa potestad de la Iglesia para redactar un artículo de fe? ¿Es acaso redactar un artículo de fe recibir una revelación nueva, como recibieron los Apóstoleso los profetas las revelaciones nuevas de la Escritura Canónica? Se responde brevemente y sin argumentos que no lo es. Es que los Apóstoles y los profetas quedaban iluminados inmediatamente por Dios. Y recibían así el conocimiento interior inmediatamente desde Dios. La Iglesia no lo recibe en cambio así, ni el concilio todo ni el Papa. Ahora bien, son iluminados de ese modo concreto, que, si consulta la Iglesia diligentemente la Sagrada Escritura y coteja un lugar con otro, sirviéndosep también además de razones naturales para determinar algo, ya sea perteneciente a las costumbres o a la le, no se le permitirá errar. Ahora bien, si quiere con todo esperar la Iglesia una revelación inmediatamente desde Dios, como lo dice Wiclef, erraría ciertamente entonces.

[L.a.9] Está con todo ahora la duda en cómo quedamos nosotros ciertos de que no se equivoca; por ejemplo, de que no erraron los padres del concilio de Nicea en la determinación de la fe. Es posible que ellos no hicieran todo lo que estaba de su parte y que no escudriñaran con diligencia las Sagradas Escrituras. Se responde a esto que estamos ciertos de que no permitirá él que la Iglesia determine algo, a menos que hubiera hecho todo lo que está en sí; es decir, obrar con suficiente diligencia.

[L.a.10] De todas formas, hay una duda, porque parece que no atribuimos entonces dignidad alguna a la Iglesia en esto. Es que tampoco le permitirá errar a una persona singular que haga diligentemente lo que está en sí. Se responde al aspecto que esto es una falsedad; es más, está en pie que una vieja, incluso un doctor de teología, haga cuanto puede y, sin embargo, se equivoque, si bien 
habría entonces ignorancia invencible. La Iglesia no puede con todo errar, ni siquiera por medio de una ignorancia invencible, en esas cosas que son de fe.

[L.a.11] Tenemos por consiguiente lo primero, que la Iglesia puede instituir un artículo y que ello no es recibir una revelación nueva. De esto se sigue en segundo lugar que las determinaciones de la Iglesia no son Escritura Sagrada. De todas formas, lleva esto consigo la Sagrada Escritura, el ser inmediatamente revelada por Dios. De todas formas, la revelación de la Iglesia no es inmediatamente desde Dios. Al contrario, lo es por medio de la Sagrada Escritura. Y por tanto, la revelación de los Apóstoles, por ejemplo la Sagrada Escritura, se comporta como principio respecto a la revelación de la Iglesia.

[L.a.12] Aquí sigue otra duda principal, sobre si tiene una autoridad tan grande la Iglesia como la tiene la Sagrada Escritura. Es que la autoridad de la Sagrada Escritura, como ya dijimos, es ahora la autoridad de los Apóstoles, que hablaban desde la revelación inmediata de Dios. Está fundada la autoridad de la Iglesia también en la revelación de Dios; pero lo está mediante la Escritura. De esto hablamos también en la misma relección. Alrededor de esto hay tres opiniones. La primera es la de Abulense, en su Introducción sobre Mateo, cuestión 13. Allí dice él que la Iglesia tiene más autoridad que un evangelista y que mil evangelistas. Y lo prueba, porque lo que es lo es precisamente por lo que es tal, siendo esto también más. Ahora bien, no creemos a los evangelistas más que por la Iglesia. Porque mandó ella que les creamos. Por consiguiente, hay mayor autoridad en la Iglesia. Y se confirma por la autoridad de Agustín en el libro Contra la epístola del fundamento de Maniqueo, en el capítulo 5. No creería, dice, a un evangelio si no me obligara la autoridad de la Iglesia.

[L.a.13] La segunda opinión se sitúa en el otro extremo. Pertenece a Cayetano, en la obra Sobre la autoridad del Papa y del concilio, cap. 4. Es que dice él que es mayor la autoridad de Juan Bautista que la del Papa y que la de toda la Iglesia. Aparece con todo como intermedia una tercera opinión. Es la de Juan Driedo, en el libro cuarto Sobre los dogmas eclesiásticos, cap. 4. Éste distingue en la Iglesia. Dice efectivamente que, si se toma la Iglesia por la Iglesia toda desde el tiempo de los Apóstoles, tienen entonces la Iglesia y las Escrituras la misma autoridad en estas cosas que son de fe, ya que la veracidad es la misma. Queda esto patente con claridad, porque los Apóstoles solos tienen una autoridad tan grande como la Escritura; es más, se trata incluso de la misma autoridad. Es que la Escritura es la aserción de los Apóstoles.

[L.a.14] Se toma de otro modo la Iglesia, por ella toda, excluyendo a los Apóstoles. Y no tiene así ella una autoridad tan grande como la Escritura, ni como la Iglesia entendida de la primera manera. Esto queda patente, porque la Iglesia no puede redactar de este modo la Escritura Sagrada como pudieron los Apóstoles. Porque no recibe la revelación inmediata como ellos mismos; 
incluso, no pude determinar algo como de fe, sino en cuanto se extrae de los dichos de los Apóstoles.

[L.a.15] Y es la misma la sentencia de Cayetano, Sobre el III, d. 24, cuestión 1. Dice en efecto que la Iglesia que está ahora no posee una autoridad tan grande como la Iglesia antigua. Y entienden así Durando y Driedo aquello de Agustín: No creería a un evangelio, etc., de la Iglesia que está ahora, sino de la Iglesia de los Apóstoles. E insinúan de esta manera que la Iglesia que es ahora no sería suficiente para determinar que una escritura es Sagrada Escritura.

[L.a.16] Y parece pretender lo mismo el señor Walden, en el tomo primero del Libro segundo, en el capítulo veintidós; es más, dice él que tienen igual autoridad; dice incluso algo admirable aquí: Que la Iglesia que es actualmente no podría aumentar ni explicar más artículos de fe, porque están ya explícitos todos, al igual que el hombre que llega a la edad perfecta no podría crecer más. De todas formas, porque esta cuestión es bastante necesaria, tanto por este artículo como por la cuestión sexta donde hemos de decir sobre la causa de la fe, respondo yo aquí por medio de algunas proposiciones.

[L.a.17] La primera. Al comparar a los Apóstoles con la Sagrada Escritura respecto a la autoridad, como la compara Driedo, no hay tal comparación. Es no decir nada eso de que tienen la misma autoridad. Es que es la misma del todo la autoridad de los Apóstoles y la de la Sagrada Escritura, como es la misma la autoridad de un hombre y su aserción. Por supuesto, es la Escritura la aserción de los Apóstoles y no tiene autoridad la Escritura si no es la que tienen los Apóstoles en cuanto los Apóstoles. Ciertamente, podía errar un Apóstol por poder pecar venialmente. Así pecó quizás Pedro en la observación de las prácticas legales.

[L.a.18] Ahora bien en cuanto redactores de la Escritura no podían errar ellos. Y por eso, cuando comparamos la Iglesia con la Sagrada Escritura, no hemos de incluir en la Iglesia a los Apóstoles. Es más, es lo mismo comparar la Iglesia con la Sagrada Escritura y compararla con los Apóstoles. De todas formas, excluidos los Apóstoles, debe tomarse la Iglesia por la que no puede redactar la Escritura. Dijimos nosotros que los Apóstoles solos pueden redactar la Sagrada Escritura por la revelación inmediata. Ahora bien, excluidos los Apóstoles, no puede la Iglesia redactar la Sagrada Escritura, por no recibir la revelación inmediatamente. De todas formas, ella puede determinar los artículos en cuanto resultan desde la Sagrada Escritura. Y hablamos nosotros de la autoridad de esta Iglesia.

[L.a.19] Segunda conclusión. Tomando la Iglesia de ese modo ya excluidos los apóstoles, no puede sostenerse la opinión de Abulense; a saber, que tiene la Iglesia mayor autoridad que un evangelista. Es que parece que Abulense toma la Iglesia para distinguirla por contraposición a los Apóstoles después de 
compararla con los evangelistas. Al fin y al cabo, la autoridad de los Apóstoles es autoridad divina. Y la Escritura Sagrada, que es la aserción de los Apóstoles, es la aserción del mismo Dios. Por eso, es aquélla la autoridad suma; es más, ni Dios tiene mayor autoridad que la Escritura misma.

[L.a.20] Y esto significa nuestro Redentor: "El cielo y la tierra pasarán; pero mis palabras no pasarán” (Mt 24,35; cf. Me 13,31; Lc 21,33). Comparó él la autoridad de la Escritura a cosas firmísimas que están en el universo: "La acogisteis no como palabra de hombre, sino como verdaderamente es" (1 Tes 2,13). Y: "Si nosotros o un ángel del cielo os evangeliza distintamente de lo que os hemos evangelizado, que sea anatema" (Gal 1,8). Como si dijera: Si nosotros mismos, los Apóstoles, o todos los ángeles del cielo; y todavía más, todo el mundo hubiera dicho lo opuesto de aquello que nosotros predicamos, no debemos creerlo.

[L.a.21] Por eso, respondemos al argumento concreto de Abulense que los evangelistas no tienen la autoridad desde la Iglesia, sino que la tienen desde Dios. Tampoco les creemos nosotros por mandarlo la Iglesia, sino por mandarlo Dios. Y al argumento de si la Iglesia no dijera que el evangelio es de Juan o de Mateo, yo no creo a los dichos del evangelista. Siendo por consiguiente la autoridad de los evangelistas por la Iglesia, le negamos la consecuencia una vez concedido lo antecedente. Quiero yo decir que la Iglesia es sólo causa de que yo crea que estas cosas son dichos del evangelista. Ahora bien, después de que creo que ése es evangelista, no creo a sus dichos por mandarlo la Iglesia, sino que me inclino desde el hábito a asentir a sus dichos como dichos de Dios.

[L.a.22] Y así, si después de creer yo que ése es un evangelista, no creo a sus dichos por mandarlo la Iglesia, sino que me inclino desde el hábito de la fe a asentir a sus dichos como dichos de Dios; y así, si después de haber creído yo que éstas son las palabras de Juan, mandara también la Iglesia por un imposible que el Verbo no se hizo carne, en modo alguno obedecería a la Iglesia, sino que creería a Juan. Hay un ejemplo. En el caso de que estuviera el Papa en presencia mía, al cual yo no conozco, y me dijera cierto hombre plebeyo: Éste es el papa Paulo, no creería yo después a los dichos del Papa por aquel hombre plebeyo, sino por la autoridad del Papa, por más que creyera que éste es el Papa por aquel hombre. Y éste es el sentido de la autoridad de Agustín, etc.; eso es, que no creería él a un evangelio si no dijera la Iglesia que esto es un evangelio. De todas formas, no se sigue de ello que la autoridad de un evangelista, o la de la Escritura, exista desde la Iglesia.

[L.a.23] Pero hay una duda a la inversa sobre si tienen mayor autoridad la Escritura o los Apóstoles que la Iglesia, excluidos los Apóstoles, que es lo que quiere el señor Cayetano. Que sea puesta entonces la tercera proposición, 
diciendo que ambas autoridades son divinas, por más que la autoridad de la Escritura y de los Apóstoles sea más inmediata que la autoridad de la Iglesia. Es que se apoya la Iglesia en las determinaciones de fe en la autoridad de la Sagrada Escritura y en la autoridad de los Apóstoles.

[L.a.24] Cuarta conclusión. La misma especie de herejía sería negar la autoridad de la Iglesia que existe ahora y del concilio legítimamente congregado que negar la proposición de un evangelio. Se prueba esto, porque sería también revelación, si bien mediata, aquello que determinara el concilio. Efectivamente, es lo mismo que revele Dios por los Apóstoles de modo inmediato la Escritura y que revele al concilio la explicación de algún artículo de fe. De todas formas, sería pecado más grave en la misma especie negar una proposición de un evangelio o de Pablo.

[L.a.25] Quinta conclusión. De alguna manera podría decirse mayor la autoridad de la Escritura que la de la Iglesia, eso es, más inmediata. Dice así Aristóteles en el primero de los Posteriores que creemos más a los principios que a la conclusión; eso es, que creemos de modo más inmediato.

[L.a.26] Está con todo como última conclusión que no puede decirse mayor simple y absolutamente después de que ambas son desde Dios. En efecto, el ser más mediata o más inmediata marca poca diferencia, dado que es tan de fe que la Iglesia no puede errar, al igual que un evangelio, aunque lo nieguen los herejes.

[L.a.27] Y tenemos así que la Iglesia puede redactar un artículo de fe y obligarnos a creer como se ha de creer a la Sagrada Escritura. Y no sólo puede esto la Iglesia antigua de los Apóstoles, sino que lo puede la Iglesia que existe en la actualidad. Es que no había ya apóstol alguno en el concilio de Nicea y tiene ahora tanta autoridad la Iglesia como el concilio de Nicea.

[L.a.28] Y se ha de responder a aquella frase de Walden; a saber, que la Iglesia no puede en la actualidad redactar ya nuevos artículos. Se entiende de que ello no es conveniente ya, si no existiera necesidad. Al fin y al cabo, es verosímil que, en un tiempo tan largo, se hallen todos ya explícitos. Ahora bien, no negaría él [el Waldense] que, si fuera necesario, podría también ahora la Iglesia explicar un artículo nuevo.

[L.a.29] Hay una segunda duda. Después de que tiene la Iglesia la autoridad de redactar un artículo de fe, se pregunta si tiene también el Papa solo la misma autoridad. Esta cuestión aparece ya entre los retóricos. Efectivamente, conceden que la Iglesia no puede errar y dicen éstos que el Papa puede errar. También, que, aunque la Iglesia pudiera explicar como de fe la Sagrada Escritura, no podría hacerlo con todo el Papa. Cierto autor moderno: Castro, expone esto ampliamente en su libro Sobre las herejías, en la palabra concilio. 
[L.a.30] La razón está en que el Papa puede ser hereje y el concilio todo no puede incurrir en herejía. Asimismo, porque se encuentran en los decretos de los Sumos Pontífices algunas cosas que no se tienen como de fe. Así las citamos el otro día sobre Inocencia en el capítulo nos alegramos, que es sobre los divorcios, donde parece ser del sentir de que Jacob mintió y de que los hijos de Israel robaron; pero que Dios los dispensó. Y Santo Tomás, incluso San Agustín, tiene lo opuesto; es más, que hay algunas veces contradicción entre los diversos Sumos Pontífices. Efectivamente, el papa Celestino determinó que, si uno de los cónyuges cae en herejía, le es lícito al otro pasar a los segundos votos. Así se tiene en el capítulo cuanto, el cual es sobre los divorcios. E Inocencio III determinó lo opuesto. Y así se tiene. Por consiguiente, uno de ellos erró.

[L.a.31] Precisa esta cuestión de una exposición más larga. De todas formas, decimos nosotros por el momento que no se preocupó Santo Tomás en el caso presente en establecer distinción entre el Papa y el concilio. Al contrario, basta el que la Iglesia puede determinar un artículo de fe. Decimos en segundo lugar que el Papa tiene la misma autoridad de redactar un artículo que el concilio. Y pretende esto también Santo Tomás. Así lo declara aquí también el señor Cayetano, aunque el concilio estuviera por encima del Papa.

[L.a.32] En primer lugar. Se halla esto expresado en aquel capítulo cuantas veces de la 24, cuestión 1 , de que cuantas veces hubiera emergido alguna duda en la fe ha de recurrirse a Pedro. Y aquello que cita Santo Tomás: "Yo rogaré por ti y tú, una vez convertido, confirma a tus hermanos" (Lc 22,32). Ciertamente, confirmar a los hermanos es hacerlos seguros también sobre las dudas de la fe. Y aquello: "Apacienta mis ovejas" (Jn 21,17). Y el oficio principal del pastor es instruir en la fe. Asimismo, porque la potestad del Papa es inmediatamente desde Dios y no desde la Iglesia, es admirable que digas tú que les hubiera dado la autoridad suprema en la Iglesia y no les hubiera dado la autoridad de interpretar la Escritura. Y se arguye últimamente, porque el Papa puede redactar perfectamente leyes en las que quedamos ciertos de que es gobernado por el Espíritu Santo y de que no puede errar. Por consiguiente, existe la misma razón sobre los artículos de fe.

[L.a.33] Por esto, concedemos al primer argumento en contra que el Papa puede ser un hereje como persona particular; pero que no puede errar como el Papa. Quiero decir yo que puede tener alguna herejía; pero que no se permitirá que la determine como la que ha de ser creída por el pueblo.

[L.a.34] Y se responde al segundo argumento en contra de la misma manera, que cuando hay desacuerdo entre los decretos de los Sumos Pontífices, no se ha de decir que algo de ellos fue determinado como de fe. Ello se debe a que hablan a veces los Sumos Pontífices como doctores solamente. Y así, 
no determinó Celestino como de fe que al otro cónyuge le sea lícito pasar a los segundos votos, sino que, cual doctor, dijo una opinión suya. Así lo hizo a menudo Inocencia, el cual fue egregio doctor. Este argumento lo trata egregia y muy abundantemente Cayetano en la segunda parte de la Apología sobre la potestad del Papa, en el capítulo décimo tercero.

[L.a.35] Existe sin embargo aquí una duda, la de que, si puede el Papa hacer un artículo, ¿por qué nunca lo hizo el mismo a solas? Parece que nunca habría necesidad de congregar el concilio y, pese a todo, nunca lo hizo sin el concilio. Se responde que el Papa puede determinar el artículo de fe consultando la Sagrada Escritura y haciendo lo que ha de hacerse de suyo según la costumbre humana. De otra forma, habría errado, como habría errado el concilio mismo. Y una persona particular no hace en las realidades humanas lo que ha de hacer de suyo si no consulta a varones probos en asuntos gravísimos. Y hace falta realizar el concilio para consultarlos. De otra forma se escandalizaría el pueblo si viera que el Papa determinara por sí cosas gravísimas. Y es esto lo que pretende aquí Santo Tomás. Así queda patente en la razón en contra de lo afirmado.

[L.a.36] Con todo, la última duda está en lo que viene requerido para que algo sea tenido como artículo de fe, sí es suficiente que sea determinado por la Iglesia o sí basta que lo hubiera recibido la Iglesia de un modo cualquiera. Se responde mediante proposiciones.

[L.a.37] La primera. No basta con que algo sea tomado y aprobado comúnmente por la Iglesia para que sea tenido como de fe. Queda patente en primer lugar desde las cosas que se leen de los santos. Se leen en público y, sin embargo, no son tenidas como de fe. Es más, hay muchas que ojalá fueran verdaderas. Asimismo, en el capítulo la santa romana quedan aprobadas obras de Agustín y obras de San Jerónimo, así como muchas otras, y no son pese a todo de fe. Es más, el decreto fue aprobado por la Iglesia, no como de fe, cual piensan los señores canonistas. Tampoco tienen mayor autoridad las obras de Agustín que están en el decreto que las obras de Jerónimo que no están en el decreto.

[L.a.38] La segunda. No basta que algo sea dudoso, se discuta en el concilio y se determine parcialmente para que sea tenido como de fe. Queda patente. En el capítulo los mayores, que es sobre el bautismo y su efecto, se discutió y se determinó que se infunden las virtudes en el bautismo; incluso, se hizo la determinación al parecer a favor de los que dicen que son cualidades distintas. Y pese a todo, no fue determinado eso como de fe, sino aprobado como opinión más verdadera de cuanto decían aquellos doctores.

[L.a.39] La tercera. Todavía no basta para que sea artículo de fe el haber sido determinado de fe en el concilio. Es que, en el concilio de Cartago, se de- 
terminó que Cristo tenía dos voluntades y, pese a ello, no es artículo de fe. Se prueba. Porque cualquiera queda obligado a saber expresamente los artículos de fe y, con todo, no es pecado que un campesino ignore que Cristo tuvo dos voluntades.

[L.a.40] Al contrario, para que algo sea artículo de fe, se requiere que sea determinado y propuesto a todos a creer y, de esta forma, todos queden obligados a saberlo. Tales son los artículos que se ponen en el símbolo de los Apóstoles. Es más, hablando propiamente no todas las cosas expresadas en el símbolo de Nicea son artículos de fe, aunque sean cosas de fe. Tal es el caso de aquello de que el Espíritu Santo procede del Padre y del Hijo. Es que no pecan los campesinos al ignorarlo.

[L.a.41] Y de esta forma, es cosa distinta ser de fe que ser algo revelado que pertenece a la fe y que, si se propusiera a alguien por la Iglesia, quedaría obligado a creerlo. Tal es el caso de toda la Sagrada Escritura y de las determinaciones de los concilios. Ahora bien, para que esto sea artículo, se requiere que haya sido ya propuesto a todos para creer de un modo tal que todos tengan que saberlo.

[L.a.42] Proposición última. No todas las cosas hechas de la Iglesia es necesario que sean tenidas como de fe. Tal es el caso de la canonización de los santos. No es absolutamente de fe que el santo que es canonizado sea santo. De todas formas, ha de creerse con todo como cierto. Porque sería el mayor error que lo tuviera la Iglesia por santo y que ella derramara preces por quien no es verdaderamente santo. Y sería así temerario y pecado grave contradecir en esto a la Iglesia. Ahora bien, no es sin embargo de fe, porque consiste en un hecho cierto nada más.

[L.a.43] Ved vosotros cómo no tiene propiamente el símbolo de Atanasia forma de símbolo, sino que tiene forma de cierta doctrina católica, siendo por eso recibido como regla de fe.

\section{b) Ms. 940}

[L.b.1] Pertenece al Sumo Pontífice la redacción de un artículo? Se da una respuesta afirmativa. Porque la edición del símbolo es la determinación de los artículos. Ahora bien, hacerlo conviene al concilio y congregar el concilio pertenece al Papa. Por consiguiente, es lo primero. Asimismo, hacer un artículo de fe es determinar como de fe una proposición que se hace salir desde la Sagrada Escritura. Ahora bien, pertenece al Papa determinar una cosa dudosa de fe. Por consiguiente, también le pertenece hacer los artículos de la fe. Ve tú la letra. Y ve tú la relección nuestra primera sobre los sentidos de la Sagrada Escritura. 
[L.b.2] En primer lugar veremos si pertenece a la Iglesia determinar un artículo de fe. Esta cuestión está en contra de los herejes y de los católicos. En primer lugar, Wiclef (como lo cita el Waldense en el tomo primero del tomo segundo en el capítulo diecinueve) dice que la Iglesia toda no tiene la autoridad de determinar algo como de fe si no es algo que está expresado en la Sagrada Escritura. Ahora bien, ponemos nosotros la conclusión de que la conclusión de Santo Tomás es de fe: Que la Iglesia puede determinar algo como de fe. Se prueba en primer lugar porque, en el concilio de Nicea, fueron determinadas muchas cosas que antes no había obligación de creer expresamente, como que Cristo es de la misma naturaleza del Padre, etc.

[L.b.3] Asimismo, hizo Cristo la promesa en el veintiocho de Mateo: "Yo estoy con vosotros hasta la consumación del mundo" (Mt, 28,20). Y en el catorce de Juan: "Yo rogaré al Padre y os dará otro Abogado, que estará con vosotros para siempre" (Jn 14,16). De esto tomamos el argumento: Cristo prometió el Espíritu Santo para que permaneciera en la Iglesia; no se ve para qué, si no es para que la Iglesia no errara al exponer la Sagrada Escritura.

[L.b.4] Asimismo, se prueba esto por la razón. Si no cambiara Cristo la condición de los hombres, no podría exponer tan claramente la Sagrada Escritura o revelarla sin quedar muchas dudas en los diversos hombres al ser la condición humana de tantas sentencias como cabezas. Así queda patente. Porque muchos herejes hacen salir desde palabras que son claras un sentido falso; por eso, es preciso que permaneciera en la Iglesia la autoridad de declarar las dudas y de declarar aquellas cosas que se han de determinar [como artículos] de fe.

[L.b.5] Ahora bien, responden los herejes que esto no era necesario porque, cuando ha de haber dudas, sería mejor esperar la revelación desde Dios. Ahora bien, esto es intolerable. Se prueba. Es que, si hubiera que esperar a una revelación al surgir una duda, debería ser de tal forma que todos tuvieran la revelación. Esto es fatuo y ridículo. Con todo, puede decirse como dicen esos que se hiciera por supuesto la revelación a uno y que él debería anunciarla a los demás. Porque bien es de fe que aquél no puede engañarnos o bien no puede, se sigue [entonces] que no se nos proveyó suficientemente sobre nuestra fe. Si decimos lo primero, decimos nosotros esto, que Dios ordenó así que fuera aquél el Papa o el concilio; [es decir,] el que determinara aquellas cosas que son de fe.

[L.b.6] Segunda duda. ¿Qué potestad es ésa de redactar un artículo de fe? A saber, si redactar un artículo, ¿es recibir una revelación nueva desde Dios inmediatamente? Respondo que no recibe la Iglesia una revelación nueva desde Dios inmediatamente nueva, sino que sólo de manera mediata tiene potestad por supuesto de hacer salir desde la Escritura alguna proposición. En 
esto consiste la autoridad de la Iglesia. Que si escudriña las Escrituras para la determinación del artículo, no pueda errar. Ahora bien, si quisiera la Iglesia determinar algo sin escudriñar la Escritura, se equivocaría.

[L.b.7] Pero diréis. ¿De dónde tenernos la certidumbre de que la Iglesia no errará en la determinación de los artículos? Se responde que quedamos ciertos desde aquello que Dios prometió de que no faltaría la fe a la Iglesia. Ahora bien, diréis: Por consiguiente no hay autoridad alguna en la Iglesia, porque a cualquiera que hubiera hecho lo que está en sí y escudriñado las Escrituras no se le permitiría errar.

[L.b.8] Se responde que es una falsedad; es más, si los santos hubieran puesto la diligencia posible, podrían errar si no hubieran estado en el concilio. Esto no se ha de admitir de la Iglesia, al ser de fe que la Iglesia no puede errar. Tenemos entonces que determinar un artículo de fe no es recibir inmediatamente una revelación desde Dios. Al contrario, la autoridad de la Iglesia es sólo indirectamente revelación de Dios; eso es, por la revelación de los Apóstoles. De estas cosas se sigue en primer lugar que redactar un artículo de fe es redactar la Sagrada Escritura. Y así, no podría redactar la Iglesia la Sagrada Escritura, al requerirse para esto inmediatamente la revelación.

[L.b.9] Ahora bien, está la duda gravísima de si tiene una autoridad tan grande la Iglesia como la tienen la Sagrada Escritura y los Apóstoles. Y parece que no, al ser la Escritura desde una revelación inmediata. Se responde por proposiciones. La primera es la del Abulense en la Introducción sobre Mateo, en la cuestión crece. Por tanto, es la conclusión del Abulense que la Iglesia tiene, mayor autoridad que un evangelista y que mil evangelistas. Y lo prueba porque un evangelio no tiene la autoridad desde sí, por ser de Mateo, etc., sino que tiene la autoridad desde la Iglesia; es decir, por mandar la Iglesia que lo crearnos. Por consiguiente, si un evangelista tiene la autoridad desde la Iglesia, tiene por consiguiente mayor autoridad la Iglesia que un evangelista. Asimismo, desde aquello de Agustín: No creería a un evangelio a menos que la autoridad, etc.

[L.b.10] Otra es la opinión de Cayetano en el Tratado sobre la autoridad del Papa y del concilio, cap. 4. Allí dice que el evangelista tiene mayor autoridad en estas cosas que son de fe que la Iglesia.

[L.b.11] Es la tercera la opinión de Driedo en el libro Sobre las escrituras eclesiásticas, cap. 4. Dice que se toma la Iglesia de dos maneras. De una forma, por toda la Iglesia desde el tiempo de los Apóstoles hasta nosotros incluyendo a los Apóstoles. Y dice de esta manera: Tan grande es la autoridad de la Iglesia como la de la Escritura. Esto queda patente por ser la Escritura las palabras de los Apóstoles y sus testimonios. Por consiguiente. Asimismo, porque dado que no hubiera habido escritura sagrada 
alguna, tendrían una autoridad tan grande los dichos de los Apóstoles como la Sagrada Escritura.

[L.b.12] Se toma de la segunda manera la Iglesia por la colección de todos tras el tiempo de los Apóstoles, sin contar a los Apóstoles. Está entonces la conclusión. No tiene una autoridad tan grande la Iglesia como la Sagrada Escritura. Esto se prueba porque no puede de esta manera la Iglesia redactar la Escritura. Por consiguiente, no tiene una autoridad tan grande como la Sagrada Escritura, ni como los Apóstoles. Pongo cinco conclusiones.

[L.b.13] Primera conclusión. Comparar la Iglesia con la Escritura excluyendo a los Apóstoles en la Iglesia es comparar lo mismo con lo mismo. Y no hay comparación alguna por deber ser la comparación entre dos. Y se prueba porque comparar la Escritura con los Apóstoles es comparar los Apóstoles con su afirmación, la cual tiene sólo la autoridad del mismo que asiente. Por consiguiente, cuando se hace la comparación de la Iglesia con la Escritura, debe tomarse la Iglesia quedando excluidos los Apóstoles.

[L.b.14] Y se confirma esto. Porque comparar la Iglesia con las Escrituras es comparar la Iglesia con los Apóstoles. Asimismo, porque la diferencia entre los Apóstoles y la Iglesia es debida a que la Iglesia no puede hacer la Escritura y pueden hacerla bien los Apóstoles. Por consiguiente, cuando comparamos la Escritura y la Iglesia, comparamos la Iglesia que no puede redactar la Escritura.

[L.b.15] Segunda conclusión. Tomando la Iglesia sin los Apóstoles no puede sostenerse la opinión del Abulense. Y no basta decir que el Abulense no tomó de este modo la Iglesia, porque el mismo se expone al comparar la Iglesia con los Apóstoles. Y pongo así la conclusión. Que en modo alguno tiene la Iglesia de esta manera mayor autoridad que la Escritura. Tampoco la tiene un ángel, ni la tiene el mismo Dios.

[L.b.16] Se prueba. Por ser la Escritura el testimonio de Dios y la afirmación de Dios. Por tanto, la Escritura es la aserción de Dios de una autoridad tan grande como el mismo es Dios. Quiso significar expresamente Cristo esto en el veinticuatro de Mateo: "El cielo y la tierra pasarán; pero mis palabras no pasarán” (Mt 24,35). Lo mismo [dice] el Apóstol en el primero a los Gálatas: "Si nosotros o un ángel del cielo os anuncie otro evangelio del que habéis recibido, sea anatema" (Gal 1,8). Por consiguiente. También si dijeran ahora los Apóstoles que Cristo no es Dios, no deberíamos creerles, aunque Dios lo dijera ahora.

[L.b.17] Con la negación de lo antecedente se responde al argumento del Abulense: Los evangelistas tienen la autoridad desde la Iglesia; por consiguiente. Porque yo no creo al evangelista porque lo dice la Iglesia, sino porque Dios lo dice. Y si arguyes: Yo no creería al evangelio de Juan sino por decir 
la Iglesia que el evangelio es de Juan, lo concedo. Por tanto tiene Juan la autoridad por la Iglesia. [Aquí] niego la consecuencia. Porque hace solamente que yo crea que éste es el evangelio de Juan. Ahora bien, después de que creo yo esto, aunque dijera la Iglesia que aquello que dice Juan es falso, yo no lo creería.

[L.b.18] El ejemplo es claro. Si estuviera el Papa en mi presencia, al cual yo no conozco, y un hombre plebeyo dice que aquí está el Papa, después de que le creo que es el Papa, si el Papa me dice algo a mí, no le creo por la autoridad del otro sino que lo creo por el Papa mismo. Hablo de la misma manera sobre el evangelio y la Iglesia. Y así es el sentido de aquello de Agustín; es decir, no creería yo a un evangelio si no me empujara la Iglesia a creer que es un evangelio. Pero está el argumento sobre la carta de Judas donde es citado el libro de Henoc, libro que no es recibido por la Iglesia como canónico. Por consiguiente, creemos más a la Iglesia que dice que no es canónico aquel libro que al apóstol [Judas] que dice lo contrario. Se responde que, de esto que un apóstol cite aquel libro, no se sigue que sea tenido como canónico por tal apóstol, sino que aquel dicho es ya canónico.

[L.b.19] De todas formas, se duda en contra sobre si tienen la Escritura y los Apóstoles mayor autoridad que la Iglesia, tomando la Iglesia sin los Apóstoles, como quiere Cayetano. Que sea sobre esto la tercera conclusión. Ambas autoridades son divinas; a saber, la de la Iglesia y la de la Escritura, aunque la autoridad de la Escritura es más inmediata que la de la Iglesia. Porque la Iglesia se apoya en la Sagrada Escritura en sus determinaciones, se sigue desde esta conclusión que la misma especie de herejía es negar la autoridad de la Iglesia y la de la Escritura. Se prueba porque ambas son autoridades divinas, aunque sería un pecado más grave en la misma especie negar una proposición Evangelio que la autoridad o determinación de la Iglesia.

[L.b.20] Cuarta conclusión. Puede de alguna manera decirse mayor la autoridad de la Escritura y de los Apóstoles que la autoridad de la Iglesia; eso es, más inmediata según el decir de Aristóteles: Todo lo que es por, etc.

[L.b.21] Última conclusión. Que si se habla simple y absolutamente, no se dice mayor la autoridad de la Escritura y la de la Iglesia. Ahora bien, tienen igual autoridad por ser ambas autoridades desde Dios. De ello se sigue que tiene tanta autoridad la Iglesia que es ahora como la Iglesia antigua de Cristo en la que estuvieron los Apóstoles; eso es, que es tan digna de fe como aqué1la. Este corolario está en contra de Driedo. Y también en contra de Durando Sobre el III, d. 24, q. 1, el cual dice que esa Iglesia no tiene una autoridad tan grande como la Iglesia antigua.

[L.b.22] Se prueba porque en el concilio de Nicea, ningún apóstol había $\mathrm{y}$, tiene la Iglesia que hay ahora una autoridad tan grande como la Iglesia que 
estaba entonces. Por consiguiente. Este corolario está en contra de Driedo y en contra de Durando Sobre el III, d. 24, q. 1, los cuales tienen que la Iglesia antigua tuvo menor autoridad que la Iglesia que es ahora. De ahí se entiende la frase de Agustín: No creería a un evangelio si no me impulsara la autoridad de la Iglesia, de la Iglesia que existía en tiempo de Agustín, no en tiempo de los Apóstoles, como dice Durando. Y así puede entenderse de la Iglesia que existe ahora.

[L.b.23] Se prueba esto porque, si la Iglesia que hay ahora no hubiera tenido una autoridad tan grande como la Iglesia antigua, no habría provisto suficientemente a la Iglesia. Aunque no se hubiera determinado efectivamente en la Iglesia de los Apóstoles que este es el evangelio de Juan y lo hubieran dejado señalado con sus nombres, no podríamos estar más ciertos de que esto es el evangelio de Juan que de un escrito de Tito Livio a no ser que la Iglesia presente tuviera la autoridad de determinar que esto es evangelio de Juan.

[L.b.24] Pero se halla en contra de esto la autoridad del Waldense en el tomo primero libro segundo, capítulo veintidós. Allí dice que puede la Iglesia determinar algo como de fe. Así queda patente en el concilio de Nicea. Y habla de la Iglesia sin los Apóstoles. Pero añade: Ahora ya no puede determinar la Iglesia porque ha llegado al número perfecto de artículos. Así, el hombre puede crecer hasta los treinta años; pero no puede hacerlo después de haber llegado a necesidad de determinar los artículos de la fe, no que tenga la Iglesia menor autoridad que la antigua. Es que, si fuera necesario determinar un artículo, podría hacerlo esta Iglesia que es una.

[L.b.25] Pese a todo, se ha de señalar que no decimos que esta Iglesia tiene una autoridad y una potestad tan grandes como la Iglesia antigua con los Apóstoles. Porque aquélla podía redactar la Sagrada Escritura, lo cual no puede hacer ésa. De todas formas, digo que tiene una autoridad tan grande; eso es, tan digna de que se le otorgue la fe como a la Iglesia antigua. Ahora bien, la cuestión es si el Papa solo puede redactar un artículo de fe sin el concilio. Y Santo Tomás parece decir que sí. Y esta cuestión está ya [planteada] entre los católicos y, sin disputa alguna, diré algunas cosas sobre esto. Ved vosotros a fray Alfonso de Castro en la palabra concilio, libro Sobre las herejías.

[L.b.26] Y todos los que están firmes en tener que el concilio está por encima del Papa tienen que el Papa solo no puede determinar un artículo de fe, sino que lo puede sólo el concilio. Lo prueban con dos razones. La primera. Porque el Papa puede errar en estas cosas que son de fe y el concilio no. Por consiguiente, no puede el Papa determinar un artículo de fe. Se prueba lo antecedente porque el Papa puede ser un hereje.

[L.b.27] La segunda razón es porque las determinaciones de los [Sumos] Pontífices no se tienen como de fe. Así queda patente en el cap. Nos alegramos 
[que empieza con las palabras de] sobre los divorcios. Allí dice Inocencio que Jacob mintió. Y tiene lo opuesto Agustín. Y en el capítulo Cuando [que es] sobre los divorcios conoce Inocencio la determinación de Celestino; es decir, que cuando uno de los cónyuges cae en herejía, puede el otro pasar a segundas nupcias. Ahora bien, reprueba Inocencio aquello y dice que no es lícito.

[L.b.28] Nosotros ponemos conclusiones sobre esto. La primera conclusión. No intenta Santo Tomás disputar aquí sobre si el Papa está por encima del concilio, porque no era famosa [esta cuestión] como lo es ahora.

[L.b.29] Segunda conclusión. Entiende Santo Tomás que el Papa solo puede determinar un artículo de fe. Y se prueba en primer lugar con la autoridad desde aquel capítulo Cuantas veces, $24, \mathrm{~d}$. 1 . Asimismo, se prueba desde aquel dicho del Señor: "Tú, una vez. convertido, confirma a tus hermanos" (Lc 22,32). Y no aparece cómo debió confirmar si no es declarando y determinando aquellas cosas que son de fe. Asimismo, desde aquello: "Apacienta mis ovejas" (Jn 21,17). Es que no podría apacentar si no se tuviera la autoridad de determinar aquellas cosas que son de fe y debieran ser creídas. Asimismo, es de fe que el Papa no puede errar en estas cosas que pertenecen a las costumbres. De la misma manera, tampoco en éstas que pertenecen a la fe. Porque Cristo dijo a Pedro: "Yo rogué por ti para que, etc." (Lc 22,32). Asimismo, porque la autoridad del Papa no es desde el concilio sino inmediatamente desde Dios. Por consiguiente, puede hacer un artículo de fe.

[L.b.30] Se responde a los argumentos en contra. Respecto al primero distinguimos que el Papa puede errar en aquellas cosas que son de fe; a saber, como persona particular. Y lo concedo así; a saber, como el Papa [no puede errar]. Y así lo concedo. O como el Papa, y así lo negamos. Esto es decir que puede tener alguna herejía [y proponerla como definición para todos]. De todas formas, nunca permitirá Dios que la proponga como de fe. Se prueba esta solución. Porque ellos admiten que el Papa no puede errar en estas cosas que pertenecen a las costumbres y al gobierno de la Iglesia, redactando las leyes, aunque pueda ser pecador como [lo es] un particular.

[L.b.31] Respecto al segundo argumento decimos que, en tales capítulos, no determina como el [Sumo] Pontífice, sino [que lo hace] como un doctor. $\mathrm{Y}$ respecto a eso de que hay disensiones entre las determinaciones de los [Sumos] Pontífices responde muy bien Cayetano en la segunda parte de la Apología del Papa, cap. 4. Allí dice que, donde hay tales disensiones, nunca queda determinado como por el [Sumo] Pontífice.

[L.b.32] Pero podría estar este argumento en contra de nosotros. Porque, si el Papa pudiera hacer esto, alguna vez lo habría hecho. De todas formas, nunca lo hizo. Por consiguiente. Se responde que el Papa podría errar si no hiciera lo que está en sí escudriñando las Escrituras. Así [podría errar] el mismo 
concilio, a menos que hiciera también lo mismo. Y por esto, es conveniente consultar a los varones sabios y los peritos de la ley. Y por eso, mal haría [el Papa] si no congregara [el concilio] para determinar algo como de fe, aunque pudiera hacerlo de suyo.

[L.b.33] Se pregunta en segundo lugar qué se requiere para que algo sea tenido como de fe o como artículo de fe. Se responde por proposiciones. La primera. Para que algo sea artículo de fe no basta que sea recibido por la Iglesia. Así queda patente en las leyendas de los santos; es más, se reciben en la Iglesia católica y anta romana las obras de Jerónimo y de Agustín. De todas formas, no se reciben como de fe. Tampoco aquellas cosas que se contienen en el decreto desde los dichos de esos doctores. Esto lo ponemos contra los canonistas que dicen esto.

[L.b.34] Segunda proposición. No basta todavía que algo fue disputado en el concilio y fue determinado hacia el lado de una de las partes para que sea artículo de fe. Así, en el capítulo Mayores [que es] sobre el bautismo y su efecto. Allí se determinó que se infunden las virtudes en el bautismo, aunque no se han de poner [tales determinaciones] como [artículo] de fe.

[L.b.35] Tercera proposición. No basta para que sea artículo de fe que una proposición sea determinada como de fe. A favor de esto señalad que hay diferencia entre una proposición de fe y un artículo de fe. Porque la proposición de fe es una proposición revelada que pertenece a la religión. Negarla sería una herejía. Así, si se negara cualquiera proposición que está en la Sagrada Escritura. De la misma manera, las determinaciones de los concilios.

[L.b.36] Ahora bien, existe una duda porque la determinación del concilio no es revelada. Se responde que se dice revelada la que se infiere desde la Sagrada Escritura. Ahora bien, el artículo de fe es una proposición determinada como de fe que todos quedan obligados a creer y que es propuesta por la Iglesia como de fe en orden a que sea creída por todos; es más, añado yo que, aunque se contenga en el concilio de Nicea, no basta para que sea artículo de fe si no es propuesta [como tal].

[L.b.37] Cuarta conclusión. Las hazañas y hechos de la Iglesia no es necesario que las tengamos en su totalidad como de fe, como el canonizar a los santos, porque esto consiste en un cierto hecho. Ahora bien, se ha de tener sin embargo aquello como centésimo; pero no como de fe. Y la razón por la que se ha de tener es muy cierta es por ser un grave error si la Iglesia tuviera a alguien por santo sin serlo. 